\title{
Comment
}

\section{LEGAL REASONING: IN SEARCH OF AN ADEQUATE THEORY OF ARGUMENT}

The proposition that every lawyer and judge engages in legal reasoning from time to time seems uncontroversial enough; surely some of them do it often. It is therefore rather surprising that no one has yet satisfactorily explicated the nature of this process. The attractiveness of many received conceptions of the process has diminished considerably as a modicum of careful analysis has finally been brouglit to bear on the problem in the last ten years. However, no unified theory has ennerged to replace the older views, and it appears that legal philosophers are far from agreed on the general form such a theory might take.

The central confusion in recent discussions of the concept of legal reasoning has been the claim that a special new form of reasoning is employed in this discipline. Modern commentators have based their approaches to this topic on the behef that this new mode of thought, soinetimes labelled "zetetic reasoning," is nonstringent; that is, that the conclusions drawn do not necessarily follow froin the premises. ${ }^{1}$

These commentaries on the reasoning process, however, blur togetler two fundamentally different issues: the degree to which the conclusion of an argument is necessitated by its premises, and the degree to which the choice of a legal position on some question is necessitated by arguments (however formulated). Modern writers appear to liave concluded that because we rarely can say that a given chain of reasoning demands a specified legal posture (in the sense that consideration of alternative outcomes would be superfluous), the arguinents employed must not entail their conclusions. Thus, it is almost uniformly believed that something other than what might be called classic deductive arguinentation is involved in legal reasoning. ${ }^{2}$

This Comment examines the claim that nondeductive argument plays any significant part in the process of legal reasoning. It offers a theory of legal reasoning as a wholly deductive enterprise which can still take account of the evident inability of legal arguments in many

1. See, e.g., Tammelo, Logic as an Instrument of Legal Reasoning, 10 JURIMETRICs J. 89, 91-92 (1970); cf. Perry, Judicial Method and the Concept of Reasoning, 19 BUfFalo L. Rev. 225, 242 (1970).

2. See note 73 infra and accompanying text. 
circumstances to demand or necessitate adopting a specified legal position.

An important preliminary step toward developing a coherent view of the process of legal reasoning is a clear statement of the aspects of the legal process under discussion; part I is devoted to that end. Part III imtroduces the more traditional views of legal reasoning and evaluates them in light of modern criticisms. Part III explores the possibility of nondeductive reasoning in the law. Part IV examines the canons of "practical reasoning" developed by philosophers as an answer to the apparent limits of more traditional conceptions of the process of legal argument. Part V presents a preliminary study, in highly abstract form, of the process of arguing by giving good reasons for legal propositions.

\section{I}

\section{The Idea of Logic and the Problem of Argument}

A welter of conflicting emotional and cognitive factors has led to the present disarray in the theory of legal reasoning. To sort out these considerations and evaluate their significance it is useful to examine the meaning and utility of logic in legal discourse and the broader bounds of the concept of reasoning.

\section{A. Logic in Perspective}

These days it is not fashionable to be a defender of reason. On all sides, the pop-culture of the 20th century deprecates the value of reasoning. ${ }^{3}$ Even among the more traditional domains of reasoning, such as the law, commentators have generally averted the attention of their readers from the reasoning process. ${ }^{4}$ In part, however, this disenchantment stems from dissatisfaction with logic and not with rationality in the broader sense. ${ }^{5}$

3. See H. Marcuse, One Dimensional Man (1964); C. Reich, The GreenING OF AMERICA (1970). The popular works do not present the more interesting criticisms of a logical defense of logic such as Godel's theorem in the mathematical sciences, which states that "the consistency of a logico-mathematical system can never be demonstrated by the methods of this system." F. WAISMANN, INTRODUCTION to MathemattCal ThInking 101 (1951). Nobel laureate P.W. Bridgman has generalized from this that "whenever we have a system dealing with itself we may expect to encounter maladjustments and infelicities, if not downright paradox." P. BRIDGMaN, The WAY THINGS ARE 7 (1959).

4. Fifty years ago, books on the practice of law stressed the canons of logic heavily. See, e.g., J. Brumbaugh, Legat. REasoning aNd Briefing 14-115 (1917). Today, however, the leading works do not. See, e.g., F. WIENER, BRIEpINo AND ARoUING FEDERAL APPEALS (1967).

5. Several rather pithy statements of the position have been offered. Thus, "[t]he life of the law has not been logic: it has been experience." 0 . Holmes, THE COMMON LAW 1 (1881). "[I]n any contact between life and logic, it is not logic that 
The analysis of legal reasoning has sometimes suffered from an initial unanalyzed conviction that rational mechanisms ${ }^{6}$ have no place in the legal sphere, ${ }^{7}$ where arguments over anibiguous rules are common and disputes about facts even more frequent. More commonly, however, recent criticisms appear to have sprung from the frustration of many actors in the legal process over the misuse of logic in some contexts and the invocation of superficially logical mechanisms to mask truly illogical conclusions in others. ${ }^{8}$ It has been suggested, for example, that widespread distrust and distaste for logic have resulted from its inflexibility and ease of abuse. ${ }^{9}$

No one would lament the distrust lawyers might have for "any type of reasoning which would force them into a straightjacket of legal determinism and compel them to apply 'clock-work' reasoning without any consideration of the moral or social considerations involved." 10 The issue, however, is the extent to which this concern bears on the question of logic's usefulness or validity. ${ }^{11}$

The value of logic in any sphere of discourse is limited by the premises available. Logic speaks to formal validity of deductions or inferences from a series of statements, and not to the truth of the premises utilized. ${ }^{12}$ Nor does logic necessitate the selection of a given premise. ${ }^{13}$ Thus, the criticisms of logic offered in a legal context, as Guest has demonstrated, ${ }^{14}$ though superficially attacks on "dryly logical extremes,"

is successful." H. LASKr, Studies In The Problem of Sovereignty 201 (1917). "[E]very lawyer must acknowledge that the law is not always logical at all." Quinn v. Leathem, [1901] A.C. 495, 506 (Halsbury, J.). "[A] page of history is worth a volume of logic." New York Trust Co. v. Eisner, 256 U.S. 345, 349 (1921) (Holmes, J.). "There is a danger that, if the Court does not temper its doctrinaire logic with a little practical wisdom, it will convert the constitutional Bill of Rights into a suicide pact." Termimiello v. Chicago, 337 U.S. 1, 37 (1948) (Jackson, J., dissenting).

6. Guest, Logic in the Law, in OXFORD ESSAYS IN JURISPRUDENCE 176 (A. GUEST ed. 1961).

7. See generally id. at 176-81. W. Zelermyer, Legal ReAsoning; ThE Evolutionary Process of LAW 2 (1960), argues that to say that legal conclusions are arrived at largely by logical reasoning is superficial. He suggests that logic enters the legal process only incidentally, and implies that when it is used logic is often virtually equivalent to arbitrariness.

Guest reports that soine authors have even claimed that the whole conception of law as a "logically consistent system is at least an impractical idea, if not an illusory fetish." Guest, supra note 6, at 177.

8. Guest, supra note 6, at 176-78.

9. Halper, Logic in Judicial Reasoning, 44 IND. L.J. 33-35 (1968).

10. Guest, supra note 6, at 176-77; see Cohen, On Absolutisms in Legal Thought, 84 U. PA. L. Rev. 681 (1936); Pound, Mechanical Jurisprudence, 8 ColuM. L. REv. 605 (1908).

11. O. Jensen, The Nature of Legal Argument 8-10 (1957); Hart, Positivism and the Separation of Law and Morals, 71 HARv. L. REv. 593, 610 (1958).

12. B. MATES, ELEMENTARY LOGIC 1-16 (1965).

13. Guest, supra note 6, at 178.

14. Id. at $178-82$. 
do not impeach logic itself; they only point out abuses of it or failures to use premises which properly take account of all of the important considerations. In fact, the criticisms of logic made in specific cases indicate the need for more, or more correct, use of logic rather than abandonment of it. ${ }^{15}$

This realization, coupled with a clear understanding of the difference between the formal validity of an argument and the truth of its premises, helps focus attention on what these rules may properly be expected to accomphish and what must be approached by other means. Public recognition of these factors may render the disillusionment with logic teinporary or at least not fundamental, leaving hope for renewed concern among legal philosophers and members of the profession generally for the adequacy of our reasoning processes. The legal crisis of our time provides an extra impetus for such a reexamination. The increasing attacks on the present judicial system from all corners of the political and philosophical arena underscore the need for defensible thought processes. Inconsistency, unfairness, and incoinplete analysis have never been satisfactory patterns in legal thought; today they are all the more visible and thus fatal to hopes of a systematic search for justice.

Assuming that the anti-rational fad and the antipathy toward abuses under the guise of logic can be rechannelled into a desire to improve the operation of the legal system, the important question becomes which aspect of the legal process should be the focal point for analysis of legal reasoning.

\section{B. The Concept of Reasoning}

Past analyses of legal reasoning have selected a single temporal step in the law process for study. Thus, soine authors have described legal reasoning in the trial court ${ }^{16}$ while others have described the reasoning of the appellate courts. ${ }^{17}$ A few writers have attempted to isolate the lawyer's logic. ${ }^{18}$ These approaches have led inexorably to an elliptical view of the concept of legal reasoning. A more general approach, not restricted to any single stage in the legal process or any specific side of the bench, has advantages beyond the coinpleteness lacking in more atomistic studies, because with completeness coines perspective.

Legal reasoning nay be analyzed not as a stage in a physical or social process but as a process itself, the process of arguinent. Argumentation describes, in general, the act or process of forming reasons,

15. Halper, supra note 9, at 34; cf. id. at 39-40.

16. See generally W. ZELERMYER, supra note 7, at 5-8.

17. E.g., E. Levi, Introduction to Legal Reasoning (1949); K. LleWellyN, The Common Law Tradition (1960).

18. E.g., J. Stone, The Legal System and Lawyers' Reasonings (1964). 
drawing conclusions, and applying them to a situation under consideration. That the practicing attorney's stock in trade is argument raises few doubts; in any aspect of a lawsuit he is avowedly an advocate, and in prophylactic counseling, reasons, conclusions, and applications are central to his advice. But the judge also engages in argument. In the search for the best rule or decision as well as in the presentation and defense of the ruling in an opinion, the judge argues for the position taken. While some opinions invite the characterization that the judge is merely explaining the decision and not arguing for it, the context of his activities contradicts this interpretation. Trial and intermediate appellate courts are traditionally subject to review by other courts. Thus, the statement of a ruling is accoinpanied by argument justifying the positions taken. These courts and the Supreme Court, which can anticipate review only by congressional legislation, reason out decisions for the benefit of other courts, lawyers, and the general public.

It is, therefore, not inappropriate to employ the broad concept of argument as the focus of an analysis of legal reasoning. This approach makes the task more difficult, in the sense that it must account for all legal reasoning. It seems likely that many of the earlier glib dismissals of, for example, deductive reasoning ${ }^{19}$ were possible only because the analytical focus of the writer was conveniently narrow. But along with the burdens imposed, broad attention to all levels of argument in the legal system permits a more cohesive and coherent pattern of observations to be drawn. The nature of legal argument cannot be described adequately by reference to part of the whole system.

A preliminary distinction of considerable force between the concept of reasoning and other processes more accurately described as post hoc rationalizing or packaging is critically important to the analysis that follows. One view of legal reasoning which has garnered support in this century is the "judicial hunclr" hypothesis. ${ }^{20}$ Sucll writers as Judge Frank have asserted that a judge makes an intuitive or emotional reaction to a case and then constructs a set of legal propositions which played no part in his decision but which legitimize the intuited result. ${ }^{21}$ This

19. See text accompanying notes 54-97 infra.

20. R. WASSERSTROM, THE JUdicial DeCision 21 (1961); Guest, supra note 6, at $187-88$.

21. J. Frank, LAW and The Modern Mind (1949); cf. Cohen, The Role of Logic in Law, 29 HARv. L. REv. 622, 631 (1916). Halper, supra note 9, at 38 states:

More cynical supporters of the judicial hunch might conclude that judges write opinions in order to conceal the actual route by which they arrived at their decision. This is reminiscent of one of the White Knight's schemes:

But I was thinking of a plan To dye one's Whiskers green,

And always use so large a fan

That they could not be seen. tricks.

The judge, then, emerges as a magician and the law turns out to be a box of 
school says that a good judge arrives at his conclusions first, and gives his reasons after. ${ }^{22}$

These and similar descriptions may be accurate reports of what happens in some cases. They are not, however, models of reasoning. This distinction is not merely semantic. The concept of reasoning has bounds which are firmly embedded in usage and our conceptual structure; whatever detractors may argue as to the validity of a given process of reasoning, none has denied the existence of a well-defimed concept. Disingenuous creation of a string of words to legitimize a decision can in no way be characterized as reasoning to a conclusion.

Professor Allen's view of legal reasoning may appear to resemble the hunch hypothesis. It is, however, different in crucial respects. Allen makes the fundamental point ${ }^{23}$ that a lawyer or judge steeped in the relevant law can often grasp the principle that properly governs a case before he can articulate the exact precepts and authorities which govern the situation. Long training and rich practical experience often permit the practitioner to see the picture before he can fill in the details. ${ }^{24}$ This model does not depict decision based on "gut reaction" or supra-rational inspiration. Rather, it stresses the syncopated maturation of related trains of reasoning supporting a given legal position as a thinker ponders a problem. In such a case, the judge would carefully evaluate his initial reaction in light of available considerations; Frank's judge has no such concern for justified decisions.

In the analysis that follows, the focus will be on reasoned argument about legal questions. No distinction will be drawn between reasoning complete before a conclusion is reached and reasoning used to test a putative solution to a legal problem. And no attention will be paid to the possible instances of nonrational or disingenuously legitimized decision procedures. The possibility of the latter practices does not justify their use.

\section{II}

\section{Tradittonal Models of Legal Reasoning}

The traditional conceptions of legal reasoning were modeled on the basic types of traditional logic. Thus, there has been much discussion of whether legal reasoning is primarily an inductive, analogical or deductive process. Many difficulties are encountered in affirming either of the first two descriptions.

22. Guest, supra note 6 , at 187.

23. C. Allen, Law in the Making 334 (6th ed. 1958).

24. Guest, supra note 6, at 187. 


\section{A. Induction}

It is commonly claimed that inductive logic is the mainstay of legal reasoning on the grounds that since the law is still largely uncodified we Inust review prior cases to determine the appropriate rules. ${ }^{25}$ Considerable imprecision surrounds the formulation of this claim, and has confused discussions of its implications. ${ }^{26}$

Induction is the inference from the observed to the unobserved, occasionally, and rather loosely, termed inferring the general from the specific. ${ }^{27}$ Its logical form is: All $X$ 's observed in the past have been $Y$, therefore the next observed $X$ will be $Y$ as well. The loose interpretation would conclude: Therefore all $X$ 's are $Y$.

The validity of induction lias been subject to serious doubt since Hume's famous attack. ${ }^{28}$ But assuming that induction is a valid practice in spite of its lack of philosophical vindication, ${ }^{29}$ a wholly different question arises as to whether anything like induction does or should go on in legal thought.

The inductive model is usually offered as a substitute for the deductive theory, which inductive theorists have found unacceptable. ${ }^{30}$ Thus, Paton wrote:

Instead of starting with a general rule the judge must turn to the relevant cases, discover the general rule implicit in them ... . The outstanding difference between the two methods is the source of the major premise-the deductive method assumes it whereas the inductive method sets down to discover it froun particular instances. ${ }^{31}$

Induction is proposed as the model for coinbing through decided cases to determine the applicable rules, an activity that plainly envisions a process of generalization. ${ }^{32}$ While there is no doubt that the courts inust refer to prior decisions to discover rules and to justify accepting propositions, that alone does not describe the process of arriving at a conclu-

25. Id. at 188 .

26. Cf. Hart, Problems of Philosophy of Law, 6 ENCY. PHn. 270 (1967).

27. See B. Skyrms, Choice \& Chance: An Introduction to Inductive Logic 1-21 (1966).

28. D. HUMe, AN ENQUIRY CONCERNIng Human UNDERSTANDING § 4 (1748); 1 D. Hume, A Treatise on Human Nature pt. 3, $\$ 6$ (1739); see B. SkYrms, supra note 27 , at $22-51$.

29. For some interesting attempts to justify or "vindicate" induction, see $\mathbf{M}$. Black, Models and Metaphors 209-18 (1962); M. Black, Problems of Analysis 191-208 (1954); H. ReICHENBaCH, THEORY OF ProbabILITY $\$ 91$ (1949); P. Strawson, InTROduction to Logical Theory passim (1964); D. Willtams, The Ground of Induction passim (1947); Stove, Hume, Probability and Induction, in Home 187-212 (V. Chappell ed. 1966).

30. Hart, supra note 26, at 269.

31. G. Paton, A Textbook OF JURISPRUdence 171-72 (2d ed. 1951).

32. Guest, supra note 6 , at 188 . 
sion. In situations where many possible rules are available, a selection must be made, and the rules of imduction offer no guidance to the selector. The use of the term induction is thus misleading if it purports to explain the whole process, especially if it suggests strong analogies with more scientific probabilistic inference. ${ }^{33}$

The court does not predict that it will decide as past cases did, yet prediction is the essence of induction. Instead, the judge must decide his case. The legal reasoner, be he attorney or judge, is not satisfied with a generalization about what past cases have held, and would hardly believe an inductive generalization that all cases in the future will hold the same. While established precedent may indeed control the outcome in many cases, there is no meaningful sense in which induction plays a part in the decision process. ${ }^{34}$ If it did, it has been suggested, there would be no need for counsel or argument, and the process would preclude the possibility of change. ${ }^{35}$

\section{B. Reasoning by Analogy}

The analogical model of reasoning is probably the most widely accepted description of argument in Anglo-American legal thought. ${ }^{36}$ An examination of the theory behind analogical reasoning facilitates assessment of its general validity and utility in legal thought. The thrust of this form of argument is an appeal to symmetry: one compares the aspects of prior situations similar to a new case and imvokes some or all of the conclusions of the previous analysis to govern the present case. ${ }^{37}$ Aristotle described analogical reasoning ${ }^{38}$ as "neitler like reasoming from part to whole, nor like reasoning from whole to part, but rather reasoning froin part to part, when both particulars are subordinate to the same term, and one of thein is known." ${ }^{39}$ The fullblown formulation of this

33. Hart, supra note 26, at 269.

34. R. CRoss, PRECEDENT IN ENGLish LAW 180 (1968): "Although the analogy between judicial reasoning with regard to case-law and these inductive processes is clear enough, the differences are sufficiently striking to cause the gravest doubts upon the propriety of describing judicial reasoning as inductive." See Dickinson, Legal Rules: Their Function in the Process of Decision, 79 U. PA. L. REv. 833 (1931); Guest, stpra note 6, at 189. See also O. JENSEN, supra note 11, at 28-31.

35. Id. at 29.

36. See, e.g., R. Cross, supra note 34, at 181-90; Guest, supra note 6, at 190.

37. See generally $\mathrm{R}$. Cross, supra uote 34 , at 181-90. The inherent danger in reasoning by analogy is the ease with which the following sort of thought-pattern may develop: the instant case turns on the scope of $X$ rule; that rule has been interpreted in such and such a manner in a previous case; therefore, that interpretation should be applied here. Obviously, attention to the decisional context of a precedent is essential to rational analysis of the interpretation it involved and to a consideration of its appropriateness in the case presently being decided.

38. He used the term "reasoning by example." Aristotle, Prior Analytics 24, $69 \mathrm{a}, 13$.

39. Id. 
view appears in the theory of legal reasoning espoused by Llewellyn, ${ }^{40}$ Levi ${ }^{41}$ and others, perhaps best characterized by the term, the "moving classification" theory.

This theory begins with the hypothesis that law consists basically of rules of varying precision derived from prior cases and existing statutes. When faced with a new case, the task of the court is to formulate a rule which comports with the precedent not yet overruled, relevant statutes, and the facts of the case before it. If the court cannot articulate a rule which accomodates all these factors, some or all of the precedent must be overruled or distinguished until it is possible to formulate a single rule which decides the new case and validates the remaining precedent. The new case is then decided according to the revised rule, the "moved" classification. ${ }^{42}$

The three main elements of analogical reasoning are central to this approach: perception of the relevant similarity between the prior case and the one before the court, determination of the "rule" of the prior case, and application of some form of that rule in the new case. ${ }^{43}$ The process becomes more coinplex, of course, as more precedents are considered and the varying rules of prior cases must be construed and reinterpreted. ${ }^{44}$

The precise techniques which are used in this form of reasoning were analyzed more fully by Karl Llewellyn. These have been concisely suminarized: ${ }^{45}$

If, for example, a court wishes to follow precedent, it could say that "the rule is too firmly established to disturb,"46 thereby also affirming that the present case was within the scope of the rule obtamed from prior cases. If it wished to avoid overruling previous cases, a court could say that each case of the type before it "must be dealt with on its own facts,"47 thus restricting the scope of the rule for which the prior cases stood. To extend the reach of an earkier case, a court could lift some general language from a prior case and put it into rule form without regard to the limitations imposed by the facts of that case. ${ }^{48}$

This model is obviously phrased in terms of an appellate court's prob-

40. K. LLEWELLYN, supra note 17.

41. E. Levi, supra note 17.

42. Id. at 1-8.

43. R. CRoss, supra note 34 , at 182 .

44. Id. at 186 .

45. Christie, Objectivity in the Law, 78 YALE L.J. 1311, 1319 (1969) (footnotes renumbered).

46. K. LlEWELLYN, supra note 17 , at 77.

47. Id. at 84 .

48. Id. at 79 . 
lems and procedures, stressing the possibility of both overt and covert treatment of the precedent. It is quite feasible, however, to adapt this theory to the lawyer's task as well. An advocate as much as a judge may search the past cases and construct an argument dealing with them in the same manner discussed by Levi and Llewellyn.

While the moving classification theory is uniformly taken to describe a fundamentally analogical process, ${ }^{40}$ that conclusion is hardly compelling. It would appear, on the contrary, that im weeding out certain precedent and fashioning a new rule, the approach of legal actors is primarily deductive. ${ }^{50}$

In any event, the moving classification theory explains the evolution of legal rules but not the reasoning process behind that developinent. It purports to describe "what the judge does" in that it specifies that he exclude some precedent, and so on, im an attempt to declare a single rule harmonizing the present case with as many past decisions as possible. Why he chooses one line of cases over another in determining which way to move the classification, however, is another matter. Levi himself has made this point abundantly clear, writing 15 years after his Introduction to Legal Reasoning was published. After reiterating the original theory, ${ }^{51}$ he launched a fully independent discussion of whether the choices made by the judge must be on the basis of "a principle that is fully satisfying im reason"; thus, he makes a clear distimction between changing classifications and the reasoning behind any given change..$^{52}$ Unfortunately, Levi's general theory does not aid analysis of the latter process, though he has made the independent comments on that as well. ${ }^{53}$

The analogical theory, like the inductive theory, does not account for the basic processes of legal argument. The analogical model's weakness is its focus on the evolution of specific rules-in this instance, substance has obscured process. At the very least this theory is incomplete; it speaks mainly of the end product of legal reasoning, not the arguments bringing it about.

49. See, e.g., R. Cross, supra note 34 , at 181 n.1.

50. See text accompanying notes 54-97 infra; cf. E. LEVI, supra note 17 , at 3 (emphasis added): "The problem for the law is: When will it be just to treat different cases as though they were the same? A working legal system must . . . be willing to pick out key similarities and to reason from them to the justice of applying a common classification."

51. The confusion in the original statement of the theory is evident: "The kind of reasoning involved in the legal process is one in which the classification changes as the classification is made." E. LEVI, supra note 17, at 3.

52. Levi, The Nature of Judicial Reasoning, in LAW AND PhLosophy 263, 273

(S. Hook ed. 1964).

53. Id. at 273-81. 


\section{The Deductive Model}

Deduction is what most people think of when they speak of reasoning. Every college student is familiar with the syllogistic statements portending the demise of Socrates which provide the common paradigm of this form of reasoning. There are many attractive features about deduction. The principle of syllogism construction ${ }^{54}$ is almost intuitively grasped, and the possible fallacies ${ }^{65}$ are well defined. ${ }^{56}$ There are also such aids as Venn diagrams, which give a spatial representation of the relationships involved, ${ }^{57}$ and truth tables, which provide a mechanical method for identifying logical tautologies. ${ }^{58}$ The unique validity of deduction as a process of argument ${ }^{59}$ however, was obscured by the mitial theories of legal thought emphasizing it. They tied deduction to a particular set of premises, creating a grand design in which the result in every case may be deduced in one fell swoop. The process of obfuscation began with John Austin.

\section{The 19th-Century Conception Then and Now}

Beginning with John Austin and continuing into the present century, many commentators on the legal process have assumed that legal rules and decisions are deduced directly from legislation, previous cases, and secondary authorities. ${ }^{60}$ They implicitly assume that all legal questions may be decided by an appeal to rules which are definite and unchanging and whose application is thoroughly predictable. Fuller has characterized this theory, which shall herein be referred to as the "19tl1-century view," as assuming "a gapless system of pre-existing law, from which a solution for every new case could be obtained by deduction."

This view asserts that various authoritative legal pronouncements form the premises of an argument the conclusion of which constitutes

54. In the example above: All men are mortal; Socrates is a man; therefore, Socrates is mortal. The construction of syllogisms in the legal context is fully described in I. Tammelo, Outlines of Modern Legal Logic (1969). Tammelo illustrates throughont the book that any argument may be put in deductive form, though he is committed to the view that noudeductive inference is more important.

55. See W. Fearnside \& W. Holther, Fallacy: The Counterfeit of ArguMENT (1959).

56. J. BrumbaUgh, supra note 4, at 36-39.

57. See, e.g., E. Abernathy, The Advocate: A Manual of Persuasion 89115 (1964).

58. See B. MATES, supra note 12 , at 87-89.

59. See text accompanying notes 81-97 infra.

aa60. J. AUSTIN, LeCtuRES ON JURISPRUDENCE passim (1832); cf. Guest, supra note 6, at 182 .

61. Fuller, Introduction to The JURISPRUdence of INTERESTs xix (M. Schoch ed. 1948). 
a valid decision. ${ }^{62}$ In such a system the applicable rule of law would operate as the major premise of a syllogism, while a proposition describing the particular facts of the case would serve as the minor premise. The judge would apply formal logic and announce the conclusion deducible from the premises. ${ }^{63}$

\section{The Defects of a Mechanistic Decision Model}

Several fundamental objections to suclı a legal process, or to such a description of the process, immediately come to mind. ${ }^{64}$ First, this approach automatically precludes considerations of justice or social utility from serving as, or being involved in the selection of, the premises of the syllogism; the premises are simply given by the legal context of prior rules and present facts. Second, such a view denies the possibility of meaningful change by limiting the judge's role to applying existing rules to the facts before him, making no provision for the creation of new rules or significant modification of old ones.

Third, the question of what the facts of the present or prior cases are presents serious difficulties. Some beheve that the 19th-century view is committed to the position that courts can only apply the rules of earlier cases to fact situations identical to the prior decisions. ${ }^{65}$ This description certainly does not resemble the actual process in the courts, where no two cases, one imagines, are ever exactly alike in every detail. It is not altogether clear that the theory is committed to the factual identity requirement, but to the extent such a requirement is imposed the theory becomes less adequate descriptively.

Fourth, problems of characterization are inherent im legal argument. Even assuming that legal rules can be found or formulated in a relatively precise fashion, their application in a given case proceeds only upon the characterization of the present case as one withm the class controlled by a specified rule. ${ }^{66}$ The characterization process is generally assumed to be a nondeductive process. ${ }^{67}$ If it is not, critics assert, the result in every case turns on nonlogical classification. ${ }^{68}$

Finally, isolation of the ratio decidendi of prior cases is no easy task. ${ }^{69}$ The 19th-century view of common law development limited precedent's binding effect to the holding or ratio of the decision. ${ }^{70}$

62. R. WASSERSTROM, supra note 20 , at 15 .

63. Id.

64. Cf. id. at 14-22.

65. Id. at 18 .

66. See generally Hart, supra note 11.

67. See, e.g., id. at 607,610 .

68. See text accompanying notes 93-97 infra.

69. Olipliant, $A$ Return to Stare Decisis, 14 A.B.A.J. $71-73$ (1928).

70. See C. AlleN, supra note 23, at 241-42. 
But the range of possible ratios derivable from previous cases is extensive. In a sense, the aspects of past rulings which dictate or control present decisions are frequently only discernible im the course of the present opinions themselves. Some argue that the process of selecting a ratio is also nondeductive. ${ }^{71}$

The attempt to describe the legal process as a single magnificent deduction thus fails. The legal rules which would form the major premise are too diverse and contradictory; the factual minor premise is often problematic. The former is the more debilitating factor. While factual premises may be formulated in yes or no form, the rule of law often is laden with exceptions. Where a strict statement is possible, the five problems discussed become roadblocks.

\section{III}

\section{Reasons AND DedUCtions}

The Austinian model of decision by deduction, postulating a process of mechanical application of given premises (the precedent and the facts), has few advocates today. ${ }^{72}$ The gross defects in this conception of the legal process, however, do not imply corresponding weaknesses $\mathrm{i}$ all uses of deduction as a form of reasoning. The unfortunate consequence of the valid attacks on the Austinian theory has been acceptance of the utterly false conclusion that the process of deduction does not and should not play a consequential role in legal thought. ${ }^{73}$ Analysis of legal reasoning leads to the conclusion that on the various levels at which argument occurs, deduction constitutes the very structure of legal reasoning. In fact, deductive organization characterizes legal argument and gives it its ultimate cogency.

\section{A. Setting Parameters of Inquiry}

Deduction has many undisputed roles to play in legal reasoning. ${ }^{74}$ The pleadings, for exaniple, inust be cast in deductively valid form. ${ }^{75}$ Reference to the primciples of deductive reasoning also exposes logical fallacies in arguments by counsel or in prior judicial opinions. ${ }^{76}$

71. See, e.g., R. WASSERSTROM, supra note 20, at 18-20.

72. But cf. H. Kelsen, The General TheORY of LAW and State (1945).

73. See, e.g., O. JENSEN, supra note 11, at 7-21; Guest, supra note 6, at 183.

74. See R. Cross, supra note 34 , at $180-81$.

75. See J. BrUmbaUGH, supra note 4, at 53-73.

76. R. Cross, supra note 34, at 180; see G. RrLe, Philosophical Arguments 5 (1945): "[A]rguments are effective as weapons only if they are logically cogent, and if they are so they reveal connexions, the disclosure of which is not the less necessary to the discovery of truth for being also handy in the discomfiture of opponents. The love of truth is not incongruous with a passion for correcting the erring." 
Yet deduction has a far more fundamental role than these initial examples suggest. The process of arriving at a concrete outcome in any legal context is an essentially deductive enterprise. Many writers who deprecate deductive reasoning have argued that it is of trivial importance to law because it is used only "at the end of the process" after the important questions determining the premises are decided by other means. ${ }^{77}$ No justification for the assumption that deduction has importance only after the premises are validated readily appears. Evidently, the assumption is made because only then are we sure that the argument's conclusions are sound. However, it seems far more plausible that a deductive framework must be adopted before any other analysis. Otherwise, discussion of the specific propositions would be undirected, if not in fact a meaningless enterprise; only creation of deductive structures permits informed selection of which propositions to examine or prove. ${ }^{78}$ The following set of successive arguments shows the usefulness of deduction in clarifying and directing inquiry.

All rules of $X$ sort should be adopted.

$Y$ is a rule of $X$ sort.

$Y$ should be the rule adopted.

To justify the major premise, on the issue of why $X$-type rules should be adopted:

All rules serving $Z_{1}-Z_{\mathrm{n}}$ policies should be adopted over other rules.

All rules of $X$ sort serve $Z_{1}-Z_{\mathrm{n}}$ policies.

Therefore, all rules of $X$ sort should be adopted.

Similar reasoning dictates the decision on whether policies $Z_{1}-Z_{n}$ predominate over another set of concerns, and so on. At each step of the progression a deductive approach helps isolate the issues and provide the answer. The analogical answer, ${ }^{70}$ " $X$ is a rule tike the rules in contexts $B, C$, and $D$ " is a thinly disguised deduction:

In all contexts similar to $B-D, Q$ rules work well.

The present context is similar to $B-D$.

Therefore, all rules of $X$ sort should be adopted.

This progression illustrates the guiding role of deduction. In formulating issues and selecting propositions to pursue, deduction structures legal thought by laying out the relationships between the various concepts involved in a question.

\section{B. Simple vs. Deductive Reasons}

In addition to its role in the structuring of legal inquiry, deduction

77. See, e.g., O. JENSEN, supra note 11 , at 16.

78. Cf. Guest, supra note 6, at 183, 196-97. See generally G. RYLE, supra note 76, at 10; Cohen, supra note 21, at 622. See also B. Cardozo, THE NATURE of tHE JUdicial Process 31 (1929).

79. See text accompanying notes 36-53 supra. 
is the framework for all legal arguments. Taking a specific legal question, "Is $C$ a $Y$ ?" (should $C$ be interpreted to be a $Y$, should $C$ be held subject to $Y$ consequences, and so on), we will adopt the proponent's side of the issue $-C$ is a $Y$-for purposes of exploring the process of reasoning. ${ }^{80}$ To focus first on the issue of what is required for something to be a reason at all, not necessarily a strong or sufficient reason, will be useful. We will denominate our side's position on the issue, $S$, and anything offered as a reason for this position, $R$.

Two areas of concern about reasons are initially apparent. First, when we say " $R$, so $S$ " we are implicitly relying on the claim that $R$ is true; we mean, in effect, that the truth of $R$ supports $S .^{81}$ For convenience, however, we abbreviate "The truth of $R$ is a reason for $S$ " as " $R$ is a reason for $S . "$

We do not test a reason by its actual validity seen retrospectively. It is perfectly proper, given the way we use the concept of reason in our language, to be wrong as to the truth of $R$ and still to have had good reason for beheving it. If in light of present knowledge $R$ appears true, we are justified in asserting it as a reason. Correspondingly, if $R$ now appears to support (render probable, and so on) $S$, but is later shown not to do so, we would not then say that our earher use of it as a reason was improper.

This lemient standard does not apply to the situation where an individual holds the belief that $R$ supports $S$, while objectively we would not say that it does. We would not say that because $R$ is his reason for $S, R$ actually is a reason for $S$ (except in the limited sense that, causally, $R$ was a reason for his beheving $S$ ).

Second, the requirement of supporting or confirming $S$ is the essential element of being a reason and is not easily met. If $R$ functions in a deductive argument for $S$, the support relation is undeniable. Thus, in conjunction with the major premise, "All $X$ 's are $Y$ 's," the premise $(R)$ " $C$ is an $X$ " is a reason deductively entailing the conclusion " $C$ is a $Y . "$

The question, then, is whether anything less than the deductive format will produce a statement $R$ that actually supports the position $S$. In a persuasive and relentless article, ${ }^{82}$ the contemporary philosopher Judith Jarvis Thomson has shown that all reasoning which provides any support whatever for a conclusion is fundamentally deductive. Her argument, couched generally in terms of factual questions, appears ap-

80. This choice, of course, is a purely heuristic device, and does not deny that the opposing counsel might develop a parallel or more persuasive contrary line of thought, or that a judge might examine both sides to find the stronger argument.

81. Thomson, Reasons and Reasoning, in PhILOsophy IN AMerica 282-303 (M. Black ed. 1965).

82. Id. 
plicable to all legal reasoning. She considers the case of a reason (again, $R$ ) for a proposition $(S)$ which is assertedly not linked deductively with $S . \quad R$, it is said, merely supports $S$. The issue is, then, the conceivable nature of that support.

Suppose $S$ is a factual conclusion, "Johnson drove the getaway car." A reason $R$ is offered for $S$ : "Johnson's fingerprints were found on the steering wheel of the car." Without constructing a deduction, we feel intuitively that $R$ supports $S$ or renders it more probable. Since $R$ does not guarantee that $S$, most people apparently assume that the support does not have deductive origins; if it were deductive, they would argue, the truth of $R$ would allow us confidently to deduce the truth of $S$.

The first important point in this regard is that deduction can operate with probabilistic premises: "If $P$, then probably $Q$ "; " $P$," "Therefore, probably $Q . "$ Thus, the fact that the fingerprint evidence $(R)$ does not guarantee the truth of the ultimate identity claim does not imply that such reasons cannot be used in deductive reasoning scheinata. ${ }^{83}$

More importantly, we face the question of what allows us to call $R$ a reason for $S$. If it is a probabilistic deduction, the support is clear: A general preimise, such as "The person whose fingerprints are found on a steering wheel probably drove the car recently" is being implicitly, or perhaps unconsciously, appealed to. From the minor premise $(R)$ the conclusion $S$ is deduced: "Johnson probably drove the car recently." $" 84$

It is of no consequence whether the person offering a consideration as a reason for $S$ articulates the major premise on which the reason depends. In the search for a theory of reasoning, the important issue is the justifiability of the argument, not the state of mind of the arguer. ${ }^{85}$ In addition, we often offer reasons which rest on solid major premises without ever thinking of the broader principle itself. That the principle exists, however, is still critical for the justification of the argument.

But suppose we assume that no implied major premise is operating in the argument " $R$, therefore $S$. " For example: "Johnson has blue eyes" $(R)$, therefore "Johnson drove the getaway car" $(S)$. It appears that without a specific major premise $R$ could not possibly be a reason for $S$. Unless a general premise resembling "If a person has blue eyes, then he drives getaway cars" can be produced, the fact appealed to is not a rea-

83. E. ABERnATHY, supra note 57, at 105 ("from such probabilities as these we decide personal, family, social, political, and national problems"); O. JENSEN, supra note 11,11 ("All $S$ is (presumably) $P$, this is $S$, therefore this is (presumably) P"); Lloyd, Reason and Logic in the Common Law, 64 LAw Q. Rev. 468 (1948).

84. Other arguments, or different formulations of the foregoing one, would be necessary to permit a stronger statement of the conclusion.

85. Hart, supra note 26 , at 270. 
son for the conclusion. Without the general premise, it is a matter of chance that the conclusion is true.

The same considerations apply in analysis of points of law. Typical reasons offered for a given rule or interpretation make reference to at least three sorts of considerations: a specific statute or legal rule, a general legal doctrine or principle, or an interest of someone in society; for example:

$R_{1} \quad$ Ever since Pennoyer the cases have held $X ; 86$

$R_{2} \quad X$ accords with traditional hearsay exceptions; $; 8$

$R_{3} \quad X$ will result in equal education for all children. ${ }^{88}$

None of these reasons supports the proposition it is designed to confirm in the absence of a major premise, however general, probabilistic, or exception-laden that premise may be:

$M P_{1}$ Precedent should be followed unless there are good reasons not to;

$M P_{2}$ Other things being equal, rules in accord with traditional hearsay exception doctrine should be adopted;

$M P_{3}$ The Constitution requires adoption of rules that give equal opportunity to all races in the area of education.

Given these major premises a conclusion may be drawn from each reason. Without them, or similar ones, there is no way anyone can say the reasons support the conclusions.

Obviously, reasons such as $R_{1-3}$ may not establish conclusively that a given legal position should be adopted because the major premises are weakly forınulated. All deductive arguments entail, or demand, their conclusions, but nothing inherent in the use of the deductive mode of reasoning guarantees that premises will be available that permit deduction of a conclusion requiring a given legal rule or settling all controversy about it. Too often the valid deduction contains a modal qualifyer like "probably," or, more weakly, "in the absence of overriding contrary considerations," 89 or, most weakly of all, "other things being equal." In addition, such phraseology as "it is desirable that $X$ " is common, as is a conclusion in terins such as "thus $X$ should be done" (meaning that it would be a good thing). While thoroughly valid deductions utilizing these locutions may be constructed, their conclusions will not be formulated strongly enough to settle a legal issue because they do not exclude other considerations.

We could construct a deductive argument that would necessitate

86. See National Equip. Rental, Ltd. v. Szukhent, 375 U.S. 311, 330 (1964)

(Black, J., dissenting).

87. See generally California v. Green, 399 U.S. 149 (1970).

88. Brown v. Board of Educ., 347 U.S. 483 (1954).

89. As, for example, in equal protection cases. 
adoption or rejection of any given legal position. But the requirement of provable premises makes this abstract ability inconsequential. Virtually all absolutely worded premises about legal rules are false. Although we could argue, "Rules which further $K$ interests must be adopted; $X$ furthers $K$ interests; therefore, $X$ must be adopted," unless the major premise is true, the argument falls. Far more often we have to rely on probabilistic or qualified premises such as "Other things being equal, rules furthering $K$ interests should be adopted." The use of probabilistic or qualified premises explains why we can have valid deductions supporting opposite sides of a single issue.

It is thus common to encounter multiple deductive arguments relating to a single legal issue, some on either side. For example, suppose a court is faced with the question of whether to adopt the felony-murder rule. Numerous arguments could support such a rule: "Rules which discourage felonies are desirable; the felony-1nurder rule discourages felomies; therefore, the felony-murder rule is desirable, other things being equal." "The policy of this state of punishing persons directly or indirectly responsible for homicide should be considered in the adoption of legal rules; the felony-murder rule punishes persons indirectly responsible for homicide; therefore, in analyzing whether the felony-inurder rule should be adopted the policy should be considered." Many others coine to mind; all support the legal position involved, but none can be said to preclude not adopting it.

We can also imagine arguments on the other side: "State policy dictates that rules prescribing pumshinent out of proportion to the crime committed should not be adopted unless absolutely necessary; the felony-murder rule imposes punishinent out of proportion to the offense; therefore, the rule should not be adopted unless absolutely necessary." "Rules causing murder convictions clog the courts because of autounatic appeal rules, a disadvantageous result; the felony-murder rule would result in more inurder convictions; therefore, adoption of the rule would be disadvantageous as it would clog the courts." These and many other obvious arguments agamst the felony-murder rule support the rejection of the rule. None of thein, however, logically precludes its adoption; that is the nature of practical deductive reasoning. But this fact does not obscure the basic point that the support relation between each argument's premises and conclusion is established by the deductive structure.

Nor does the obvious necessity of proving or arguing for the major or minor premises vitiate the value of the deductive procedure, because only deductive argument will provide any reasons for the premises. ${ }^{00}$

90. A few writers have argued that legal reasoning cannot involve the use of deduction because legal rules are not true or false in the ordinary sense. See, e.g., F. Castberg, The Problems of Legal Philosophy 52 (1958); O. Jensen, supra note 
The same considerations apply to each succeeding level of argument. ${ }^{91}$ And while it is no doubt true that many of the premises may be shown to be only probably true, the deductive mode does at least provide a guarantee that there is some support for each conclusion, something a nondeductive reason-giving process can never do in the law.

The existence of numerous deductions, some supporting and others opposing a given legal position, does not imply that the outcome rests on some other factor or that it is approached in some other manner than deduction. The resolution of issues subject to deductive reasons on both sides is also a deductive process. ${ }^{92}$ The major premise of arguments comparing reasons resembles "The legal position supported by the stronger reasons is justified"; we then proceed to compare the various reasons offered by the many applicable deductions made in support of or against the legal position. The nature of this process and the justification for adopting the major premise itself will have to be examined. Before turning to this topic, however, one element of the basic role of deduction remains to be discussed.

\section{Classifications in Penumbral Cases}

Following Hart, ${ }^{33}$ many writers have sought to distinguish "core" cases under a legal rule, about which little serious dispute is possible, from "penumbral" cases, where the applicability or meaning of a given rule is a matter of legitimate contention. They assert ${ }^{94}$ that in the most common situation, penumbral questions, deduction has at most a trivial role to play; only after the real issue in the analysis has been decided (e.g., $C$ is a case of $X$ ) is a conclusion $(C$ is therefore also a $Y$ ) deducible. The shallowness of this view underscores the fundamental role of deduction in legal reasoning. None of the studies thus far undertaken

11, at 18-19; Guest, supra note 6, at 186; H.L.A. Hart has answered this claim: This view depends on a restrictive definition, in terms of truth and falsehood, of the notion of a valid deductive inference and of logical relations such as consistency and contradiction. This would exclude from the scope of deductive inference not only legal rules or statements of law but also commands and many other sentential forms which are commonly regarded as susceptible of logical relations and as constituents of valid deductive arguments. A1though considerable technical complexities are involved, several more general definitions of the idea of valid deductive inference that render the notion applicable to inferences the constituents of which are not characterized as either true or false have now been worked out by logicians. In what follows, as in most of contemporary jurisprudential literature, the general acceptability of this more generalized definition of valid inference is assumed.

Hart, supra note 26, at 269.

91. See text accompanying notes $78 \& 79$ supra. The unsupported contrary assumption is found in J. STONE, supra note 18, at 56.

92. See text accompanying notes 167-76 infra.

93. Hart, Ascription of Responsibility and Rights, 49 Proc. ArISTOTELIAN Soc'Y 171 (1949).

94. E.g., R. CRoss, supra note 34 , at 178. 
has satisfactorily analyzed the general nature of the process by which the penumbral questions are decided. Let us assume that the argument "All $X$ 's and $Y$ 's, $C$ is an $X$, therefore $C$ is a $Y$ " contains the penumbral question "Is $C$ an $X$ ?"

Even those who recognize an important role for deduction in legal argument believe that the validity of the middle premises in such arguments can never be shown or controverted by deductive means alone. ${ }^{05}$ Hence, analysis of such propositions is said to involve a process of classification which is nondeductive from beginning to end. ${ }^{96}$ However, no one has identified any logical impediment to use of the deductive mode in these situations. Surely a common form of argument by a judge or lawyer on the subject of the proposition " $C$ is an $X$ " follows this form:
All $B$ 's are $X$ 's
$C$ is a $B$
Therefore, $C$ is an $X^{97}$

When such a direct deduction is unavailable, deductive reasons for the selection of a given classification still provide a cogent form of argument for selecting one view over another: "Terms of the No vehicles in the park' law should be interpreted, if possible, to keep the noise level down; classification of a go-cart as a vehicle under the terms of the ordinance would keep the noise level in the park down; therefore, the term 'vehicle' in the ordinance should be interpreted, if possible, to encompass a go-cart."

As in the earlier contexts, deduction here may not conclusively establish a particular classification. But support for one or another classification is undeniable when a deductive argument is mounted. No nondeductive set of considerations can offer even that much.

Deduction thus operates in all arguments in the legal sphere. It is useful at the levels of utmost generality to define issues and point the way to subsidiary concerns that must be dealt with before a desired issue may be reached. In individual arguments only deduction gives meanmg to the concept of a reason. Without it, no statement may be said to support a legal position.

95. See, e.g., R. WASSERSTROM, supra note 20 , at $12-38$.

96. Dickinson, supra note 34, at 1060-61; Guest, supra note 6, at 193-94.

97. For example, suppose a case presents the issue of a majority stockholder's alleged liability for failure to protect the interests of minority shareholders. The plaintiff's argument runs: Defendant liad a duty to protect us or, at least, provide us witht he opportunity to avoid economic injury; defendant failed to perform that duty; therefore defendant is liable for the damages we incurred. The issue whether defendant had such a duty depends on characterization of it as a fiduciary; plaintiff argues that all fiduciaries have such a duty, defendant was a fiduciary, therefore defendant had such a duty. Was defendant a fiduciary? This presents the classification problem. No doubt analogies and other devices might be used to argue that a majority shareholder is a fiduciary. However, plaintiff might also couch the argument in straight forward deductive form: 


\section{IV}

\section{Practical Reasoning: The Beginnings of A CoMprehensive Theory}

The demonstration that to give reasons for a legal position means to give deductive reasons for it has also made it evident that although deductive arguments entail their own conclusions, they are not necessarily susceptible to strong enough formulation to settle a legal issue. A simple deduction may occasionally settle some aspects of a problem if the premises are uncontroverted; thus: "Anyone keeping dangerous animals on his land is strictly liable for damage caused by them; Evans kept a tiger (a dangerous animal) which got loose and mauled Cook; Therefore, Evans is liable for the damages caused." But in controversies involving disputed propositions of law, and often even in factual determinations, competing deductive reasons may be produced for and agamst a proposition. In these situations we give arguments (deductive reasons) for or against other reasons. We will now analyze this process (here called practical reasoning) which involves giving reasons which do not compel or necessitate a given legal outcome but which count in favor of or against it.

The defensibility of this process of reasoning rests on an initial showing that reliance on reasons is proper and important in the legal sphere. This inquiry provides the foundation necessary for the subsequent discussion of the two fundamental problems created by the operation of practical deductive reasoning: what good or sufficient reasons for a given legal position are, and low a decision is justified. The remainder of this part of the Comment is devoted to a discussion of essential background material on the propriety of reliance on reasons and the historical context of the practical reasoning problem. Part V will deal with the question of good reasons and justified decisions.

\section{A. In Defense of Ingenuous Reasoning}

The question why we should seek to justify legal propositions with sound reasons is bound up witl the sceptical attack on reasoning in general. ${ }^{98}$ The answer to botli objections rests on the same ground, though the two attacks raise somewhat different questions.

All parties with power to greatly affect the value of minority shareholders' interests are held to fiduciary responsibilities; majority shareholders have this power: therefore a majority shareholder is a fiduciary. Cf. Jones v. H.F. Ahmanson \& Co., 1 Cal. 3d 93, 460 P.2d 464, 81 Cal. Rptr. 592 (1969).

98. Scepticism being, in the widest sense, the theory that we really know nothing, so reasoning about things is superfluous. In the legal sphere "rule scepticism" has had many adherents in this century. See B. Cardozo, THE Nature of the Judicial Process (1921); K. Llewellyy, Jurisprudence: Realism IN Theory and Practice 
A large gap, both intellectual and emotional, separates the theoreticians of Realism ${ }^{90}$ from thinkers espousing rational argument as a valid mode of discourse. ${ }^{100}$ The two levels on which this contrast may be seen are the basic myth and functional explication levels.

\section{The Scepticism of the Radical Legal Realists}

Jerome Frank and his more radical followers attacked the "basic myth" of modern thought about the legal system: the belief that any meaningful reasoning about rules is going on. ${ }^{101}$ Committed to the proposition that the judge lias unlimited freedorn in making a decision, these thinkers proposed a factual, psyclioanalytically oriented approach with decisions rendered on the basis of needs. They entirely rejected decision by reasoning in favor of decision by a psychological expert. ${ }^{102}$ Further, their expert has no need for rules, simce he bases his judgment solely on facts about needs, both individual and social. ${ }^{103}$ According to Professor Rodell, law is a "high-class racket," "a hoax," "streamlined voodoo," and "word inagic"; consequently, he felt that rule by social workers and psychologists would be a preferable alternative. ${ }^{104}$ These thinkers believe that reasoning with rules is illusory because to them rules are unreal symbols. ${ }^{105}$

Professor Frankena has ably discussed the incoherence of this form

(1962). The position of the rule sceptics is summarized by Llewellyn, "[R]ules are important so far as they help you predict what judges will do. That is all their importance except as pretty playthings." K. Llewellyn, The BRAMBLe BuSH (2d ed. 1951). The underlying theory

amounts to the contention that, so far as the courts are concerned, there is nothing to circumscribe the area of open texture: so that it is false, if not senseless, to regard judges as themselves subject to rules or "bound" to decide cases as they do. They may act with sufficient predictive regularity and uniformity to enable others, over long periods, to live by courts' decisions as rules. Judges may even experience feelings of compulsion when they decide cases as they do, and these feelings may be predictable too; but beyond this there is nothing which can be characterized as a rule which they observe. There is nothing which courts treat as standards of correct judicial behavior, and so nothing in that behavior which manifests the internal point of view characteristic of the acceptance of rules.

H. HART, THE CONCEPT OF LAW 135 (1961).

99. Realism is the view that the important feature of the legal system is what happens, not why. It is committed to the belief that we cannot know what leads to decisions and that even if we could determine the reasoning behind legal positions that fact would be unimportant because judges do not rely on reasons. See generally, W. FnuedMANN, LEGAL THEORY 292-311 (5th ed. 1967).

100. Cf. Shklar, Decisionism, in Rational Decision 3, 7 (Am. Soc'y for Pol. \& Legal Phil., Nomos VII, C. Friedrich ed. 1964).

101. J. FRANK, supra note 21, at 170-85, 222-28, 243-60.

102. See generally id.; T. ARnold, The Symbols of Government 21, $46-47$ (1935).

103. See generally J. FRANK, supra note 21.

104. F. Rodell, Woe UNto You, LAWYeRs!, 14, 16-17, 121 (1957).

105. Id. 
of scepticism. ${ }^{106}$ Beginning with Aristotle, philosophers have recognized that one major function of human discourse is rational argument:

The mere making of sounds serves to indicate pleasure and pain, and thus a faculty that belongs to animals in general. . . . But language serves to declare what is advantageous and what is the reverse, and it therefore serves to declare what is just and what is unjust. It is the peculiarity of man . . that he alone possesses a perception of good and evil, of the just and the unjust, and of other similar qualities; and it is association in [a conımon perception of] these things which makes a family and a polis. ${ }^{107}$

In a more modern era, Hume argued that among the many vocabularies of man there is one which involves a "peculiar set of terms" invented to express umiversal sentiments of approval or censure and other concepts related to human problems. ${ }^{108}$ Hume was thinking of moral judgments such as are involved when one "bestows on any man the ephithets vicious, or odious or depraved,"109 but the poimt extends also to other terms as well, such as "true" or "valid," "probable," "desirable," "entailed," "real," and their opposites.110 For as Hume stated of the use of ethical terms, in using any such concepts one

speaks another language, and expresses sentiments, in which he expects all his audience are to concur with him. He must here, therefore, depart froin his private and particular situation, and inust choose a point of view, common to him and others; he must move some universal principle of the hunian frame, and touch a string to which all mankind have an accord and symphony. ${ }^{111}$

Radical scepticism argues that to use such discourse is self-deception, escapism and other-directedness. ${ }^{112}$ Frankena responds that "the confident though careful use of this peculiar language [is] the chief source of such humanity as man may have."113 Moreover, a thoroughgoing scepticism appears doomed to self-contradiction. ${ }^{114}$

106. Frankena, Decisionism and Separatism in Social Philosophy, in RATronaL Decision 18 (Am. Soc'y For Pol. \& Legal Phil., Nomos VII, C. Friedrich ed. 1964).

107. Aristotle, The Politics of Aristotle 6.

108. D. Hume, AN ENQUiry Concerning the Principles of Morais § IX, pt. I (1751).

109. Id.

110. See Frankena, supra note 106, at 22.

111. D. HuME, supra note 108.

112. Frankena, supra note 106, at 22.

113. Id.

114. Id.:

Of course, there are familiar arguments against the credulous use of words like "good," "right," "justified," "valid," "true," "real," and "rational," with their implicit claims to a hypothetical consensus with others-for example, the argument that all such claims are false and illusory. . . . It must suffice here to point out that radical decisionism cannot assert itself in the public arena, as it has and does, unless it inconsistently talks in just the manner it condemns. For if it speaks there at all, as it willy-nilly must, it must contend that claims to 
Radical legal realism has faded from prominence, though parallel skepticism about reasoning is certainly evident in some spheres of contemporary thought. ${ }^{115}$ The crucial point in response to the Realist thesis is not that decisions qua decisions are not causes of inner conflict and inescapably personal choices: they are. This aspect of life, however, does not lead to the conclusion that decisions may not be validly criticised as to the reasons for which they were made. This point is miportant in analyzing the claims of milder Realists who attack the lesser myth of rational decisionmaking in the legal process.

\section{The Value of Having Good Reasons}

The mild Realist ${ }^{116}$ attacks the functional explication of legal reasoning given by advocates of principled decisionmaking and points to the fact that legal arguments cannot be all in the form of an absolute deductive syllogism completely settling a legal issue. This much we may grant. Such an admission, however, is wholly compatible with the view that reasoning with rules should guide and control arguments and decisions. It does not follow that legal decisions must be arbitrary or irrational, ${ }^{117}$ thereby eliminating altogether the need for considering reasoning. Wasserstrom has named that mistaken pattern of thought the irrationalist fallacy. ${ }^{118}$ Earlier discussion illustrated the perfectly feasible deductive arguments available to deal with legal questions. ${ }^{110}$ If the essence of the milder Realist clann is simply that often actors in the system do not engage in such arguments, we are reminded of the judicial

intersubjective validity are mistaken or dishonest, that it is true that the appeal to reason and rules is just pretense and self-deception, that pretense and selfdeception and escapism are reprehensible, and so on. But for it thus to use words like "mistaken," "dishonest," "true," "pretense," "self-deception," and "reprehensible"-not to mention "authentic"-is illegitimate. If it is to be consistent, which it cannot be, it must construe even its own theses and pronouncements as mere externalizations of private beliefs, wishes, decisions, commitments, and the like, that is, as purely autobiographical self-revelations or self-creations.

Id. at 23 .

115. See authorities cited note 3 supra.

116. E.g., Holmes, The Path of the Law, 10 HARv. L. Rev. 457 (1897).

117. Frankena, supra note 106 , at 25 ; cf. R. HARE, The LANGUAGE of Moruls

69 (1952).

118. R. WASSERSTROM, supra note 20, at 24. The author contimues:

An appeal to formal logic is equated with an appeal to criteria of rationality or reasonableness, and it is concluded that because the courts cannot have used formal logic to select or formulate legal premises, the courts cannot have appealed to any rational or objective criteria when engaged im these undertakings. Perhaps the philosophers who insist so vehemently that the deductive theory is hopelessly wrong are not wholly serious on this point, but they do say that most of the important problems which arise in the decision of cases must be settled by the court in an arbitrary fashion becalse they cannot be settled by appealing to the canons of Aristotelian logic.

119. See text accompanying notes 72-97 supra. 
hunch problem: ${ }^{120}$ The fact that available means of rational argument are sometimes ignored militates for more emphasis on their use, not for drawing the conclusion that reasoning does not work. In constructing a theory of legal reasoning we are seeking an explication, a statement of what is possible and a suggestion of what should be done given that fundamental limitation. We thus have dual responsibilities; describing accurately the forms of argument in fact available for legal discourse and suggesting that the valid ones ought to be used. The Realist thesis is unconvincing as a blanket description and worthless as an explication.

Not only is there no logical defect in relying on reasons, but in addition there are concrete benefits flowing from attention to reasons for legal action. Not the least of these is that the dynamics of public obedience to rules and public satisfaction from so domg are no doubt inproved when the rule is supported by good reasons. Moreover, it is not unlikely that the preservation of substantive rules, which even the sceptics feel important, such as those preserving human dignity and the right to a fair trial, depends on requiring rational weighing of reasons in legal argument. ${ }^{121}$ A philosophy which demies the efficacy of reason has no answer to the tyrant who attacks important principles; it cannot begin to argue against him because its discourse is limited to exclamations of the form "I feel that this is wrong." Only in a system where reasons count could an effective statement be made. Treating rational beings rationally, therefore, has broad implications.

\section{B. Growth of the Practical Reasoning Concept}

The realization that deductive arguments may fail to settle a legal issue even though each argument yields conclusions necessarily true given the preinises, raises issues which can only be approached in light of the development of the practical reasoning concept.

\section{The Aristotelian Tradition}

Two aspects of Aristotle's thought are especially significant for the understanding of practical reasoning: his discussion in various works of "practical argument," and his treatment, in the Rhetoric ${ }^{122}$ and the Top$i c s^{123}$ of the principles of rhethorical argument. The former provides an interesting analysis of one form of applied deductive reasoning while the latter presages the contemporary "New Rhetoric" movement.

Aristotle's division of argument into two categories, dialectical and

120. See text accompanying notes 20-24 supra.

121. Ladd, The Place of Practical Reason in Judicial Decision, in Rational DEcision 126, 144 (Am. Soc'y For Pol. \& Legal Phil., Nomos VII, C. Friedrich ed. 1964).

122. Aristotle, Rhetoric.

123. Aristotle, The Topics. 
rhetorical, is usually greatly emphasized. ${ }^{124}$ The former is deductive reasoning with premises which are not certain; they are probably true or true in general. ${ }^{125}$ The conclusions which may be drawn from such arguments are logically valid, of course, but will not necessarily be true. Aristotle labelled the premises of dialectical reasoning topoi and gave many examples of them in the Topics. ${ }^{128}$ They are usually commonplace inaxims not unlike many found in the law. ${ }^{127}$ The second category of argument, rhetoric, attempts to persuade audiences, using both dialectical means and less logic-oriented oratorical devices. ${ }^{128}$

The limitation of analysis to these two discussions by Aristotle obscures a complete picture of the actual theory of practical reasoning which Aristotle held. For Aristotle, practical reasoning described a process of dehiberation usually left unexamined in everyday life. ${ }^{120}$ The conclusion of the reasoning was always a statement prescribing action, in the form " $X$ must do $Y$ " and the premises were often in normal valid syllogism form. ${ }^{130}$ However, he intended ${ }^{131}$ the concept of practical reasoning to extend to the following sorts of arguments:

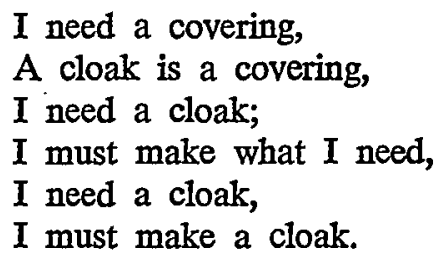

The premises involved in this argument could no doubt be tightened up to more closely resemble the normal deductive format. ${ }^{132}$ But in that revised form, the argument would rest on dubious premises. If it included as a first premise "I need all coverings" and as a fourth, "I must make everything that I need," the conclusion would follow, but these premises would hardly be true. They are overly broad and ignore both the many possible means of achieving the desired end and possible impact of other factors.

124. See, e.g., Christie, supra note 45 , at 1327.

125. Aristotle, supra note 123, bk. III, ch.1, 100a30ff, bk. I, ch. 10, 104a5ff.

126. E.g., "What is desired for its own sake is more desirable than what is desired only for its effects." Id. bk. III, ch. 1, 116a27-31. "Of two things not otherwise distinguishable, that which produces the more beneficial effects is the more desirable." Id. bk. III, ch. 2, 117a5-15.

127. An interesting bisting of typical maxims of statutory construction is found in Llewellyn, Remarks on the Theory of Appellate Decision and the Rules or Canons About How Statutes are to be Construed, 3 VAND. L. Rev. 395, 401-06 (1950).

128. An appeal to prejudice, for example.

129. Anscombe, Thought and Action in Aristotle, in Aristotle's Ethics 56, 64 (J. Walsh \& H. Shapiro eds. 1967).

130. Id. E.g., "Every man has got to walk, I am a man, I have got to walk."

131. Id. at 65 .

132. Id. 
It appears that in his enthusiastic attempt to explain the obvious convincing power of practical reasoning Aristotle overlooked some aspects of practical arguments. ${ }^{133}$ The differences between classic deductive and practical reasoning do not render the description "reasoning" inapposite to the latter. As Aristotle saw, the logical cogency and motivating power of such arguments are extensive, but there are many issues which cannot be decisively settled by simple deductive arguments because of certain weak fact premises, gaps in our knowledge, or the existence of viable alternative conclusions. Aristotle thus identified the importance, though not the mechanisms, of practical reasoning in his discussion of the concept.

\section{Argument as Rhetoric: Persuasion Without Justification?}

A revival of rhetorical persuasion as a theory of practical reasoning has occurred in this century in the aptly yclept New Rhetoric movement. It poses the question of whether a nondeductive theory can satisfactorily account for legal reasoning. Beginning with the work of Viehweg ${ }^{134}$ and gaining broad acknowledgement following a spate of publications by the contemporary Belgian philosopher Chaim Perelman, ${ }^{135}$ the New Rhetoric doctrine advocates modernization of Aristotle's topoi, extending the concept and applying it to present day contexts.

Rhetoric is the art of persuasion, ${ }^{136}$ and thus the test of a good argument, say these thinkers, is whether it succeeds in convincing the audience to whom it is addressed. ${ }^{137}$ As a theory of legal reasoning, the New Rhetoric has a deceptively rationalistic basic premise: Perelman has written that "the capacity for deliberation and argumentation is a distinguishing mark of rational beings." ${ }^{\prime 38}$ The theory adumbrating this enterprise, however, puts a very different emphasis forward by stressing persuasive power as the determinant of a good argument.

An underlying defect in the Rhetorical Theory is illustrated by the question of strength in a rhetorical argument. The mere number of reasons anassed cannot be an index of the strength because reasons vary in persuasive power. Perelman's singularly unhelpful statement on this subject is that a strong legal argument is one which uses prece-

133. Id. at 66.

134. T. VIEHWEG, TOPIK UND JURISPRUDENZ (1953).

135. See, e.g., C. Perklmai \& L. Olbrechts-Tyteca, The New Rhetoric, Treatise on ARgumentation (1968) [hereinafter cited as Treatise] (references to the French edition will be made in brackets); cf. C. Perelman, The Idea of Justice aNd The Problem of Argument (1963).

136. See generally Aristotle, supra note 122.

137. See generally TrEATISE $\$ \$ 1-9,21,26,27$.

138. C. PERELMAN, supra note 135 , at 134. 
dent. ${ }^{139}$ Since the New Rhetoric is oriented to persuasion, the natural tendency of the theory is to define strength in terms of the ability to move a given audience. This doctrine, however, highlights the fundamental defect in a rhetorical theory of argument. In historical perspective, the search for a theory of reasoning to complement the established logical traditions is seen as an attempt to find a justified mode of argument. ${ }^{140}$ Rhetorical persuasion can never provide such a justification. From the time of Plato and Aristotle, the goal of many philosophers has been to distinguish between modes of discourse which do carry persuasive power and modes which ought to have this effect. ${ }^{141}$ The New Rhetoric outlines means of persuasion but not means of justifying the persuasion.

Neither the ability of an argument to persuade a given group nor the competence of the audience or rhetorician provide a safeguard for the tenability of arguments tested solely by persuasive power. Some commentators have argued that reasoning with topoi requires a special integrity on the part of the reasoner, and such attitudes as tact, moderation, circumspection, attentiveness, penetration, readiness to reconsider positions, empathy, and good scholarship. ${ }^{142}$ However desirable these attributes may be in any context, a theory of reasoning which requires them to justify persuasion is unreahistic at best and probably disingenuous. In the legal sphere especially, where conflicting opinions often exist on broad principles of justice and specific matters of fact, the expectation that these qualities may be met in adversary contexts appears particularly naive.

Other aspects of the theory are also disturbing. At some points of the literature, some basic concepts are confused. While making the claim that the sort of reasoning which must be examined in the law and elsewhere is the informal or nonstringent (nondeductive) argumentation which operates in many familiar contexts, Perelunan states as a premise that: "Dehiberation and argumentation are opposed by their very nature to necessity and evidence."143 While the former is by definition a very different sort of question, nothing at all suggests that the latter is not a normal tool and topic of practical reasoning. In seeking to explicate a form of nondemonstrative proof which is nevertheless cogent in a

139. Perelman, l'teal de Rationalité et la Règle de Justice, 54 BuLLETIN DE LA SOCÍTÉ FraNÇAISE de PHILOSOPHIE 15, 16 (1960).

140. Tammelo, The Rule of Law and the Rule of Reason in International Legal Relations, in LA ThEORIE De L'ARgUMENTATION 335, 342-43 (1964).

141. Id. at 343.

142. E.g., id. at 348; cf. Belval, Libres Remarques sur L'Argumentation, 4 Revue International de Philosophie 336, 347 (1961); Patterson, Logic in the Law, $90 \mathrm{U}$. PA. L. Rev. 875, 894 (1941). See also H. JoHnston, JR., PHLOSOPHY AND ARGUMENT 123-37 (1959).

143. C. PERELMAN, supra note 135 , at 134 . 
given reasoning context, we are concerned precisely with evidence problems.

A more basic difficulty afflicts the New Rhetoric as a theory of legal reasoning. Perelman begins the Traité by asserting that his approach effects a rupture with the Cartesian view of reasoning taken for granted during the last 300 years. ${ }^{144}$ The emphasis on rupture is significant because Perelman apparently holds that his theory is an exclusive description of reasoning on jurisprudential (and other) matters, ${ }^{145}$ and not merely a theory describing a portion of legal rationality. However, the presentation does not argue that this theory of argumentation fully describes legal reasoning; it simply assumes so. ${ }^{146}$

The poverty of the rhetorical approach in dealing with legal questions is well-illustrated by Perelman's treatment of his favorite topic: the idea of justice and the problem of argument. ${ }^{147}$ Perelman states that each conception of justice has value judgments behind it but that neither these value judgments nor any basic values of the entire system can be subject to any "rational criteria."148 In later writings limits to this doctrine of the fundamental arbitrariness of value judgments appear, ${ }^{149}$ but the tremendous difficulty of finding a way of reasoning about values remains. ${ }^{150}$ Perelman's answer is to shun naturalistic approaches and focus on the historical and social character of the inquiry or knowledge under discussion. ${ }^{151}$ Reflecting on the historical situation, Perelman adopts the position vis-à-vis justice that only change in the present structure needs justification..$^{152}$ This view is a far cry from meaningful dialogue about justice, and an historico-social approach promises to be no less vacuous when applied to conflicting values in inore concrete legal controversies; one continues to confront norms imcapable of further analysis. ${ }^{153}$ The theory's answer to this problem is simply that differing value judgments are a factor inherent in the theory of prsuasive rhetorical argument. ${ }^{154}$ The rhetorical theory is thus not an attractive technique for settling disputes. Perelman concedes that "only force seems to be able

144. Treatise 1.

145. See, e.g., C. Perelman, supra note 135 , at 155-57.

146. See generally Stoeckli, Topic and Argumentation, 54 ARCHV FUR RECHrsUND SozIAL-PHILOSOPHIE [ARSP] 581, 588 (1968).

147. See, e.g., C. Pereldan, supra note 135.

148. See generally id. at 15 .

149. Cf. Hart Introduction to C. Perelman, supra note 135, at ix.

150. C. Perelman, supra note 135 , at 57.

151. Jenkins, Book Review, 9 NAT. L.F. 186, 192 (1964).

152. Perelman, Ǔber die Gerechtigkeit, 51 ARSP 167, 173 (1965); cf. Stoeckli, supra note 146, at 589 .

153. Perelman, supra note 152, at 203; Perelman \& Olbrechts-Tyteca, De la Temporalité-comme Caractère de l'Argumentation, 1958 IL TeMPo, ARCHIvo DE FraSOPHIA 125.

154. See Perelman, supra note 152, at 207; Stoeckli, supra note 146 , at 590. 
to decide conflicts between relative values,"155 which may explain the theory's emphasis on the consent of rational beings as a test of propositions. ${ }^{158}$

Perelman recognizes in his study of argumentation that the major problems of legal reasoning arise when there is a conflict between two or inore existing rules, ${ }^{157}$ when it is argued that an otherwise applicable rule is invalid, ${ }^{158}$ and when there is no clearly applicable legal rule. ${ }^{150}$ He does not, however, attempt to deal with these situations beyond the point of stating that normal techniques of rhetoric will apply. Perelman does not discuss problems of applying law to concrete factual situations because of his belief that this task is easier than any of the three interpretative problems, ${ }^{\mathbf{1 6 0}}$ and he holds that analogical reasoning is an imsignificant aspect of legal thought, essentially equivalent to giving examples of a general rule. ${ }^{161}$ Given these limitations, Perelman's work has comparatively little to say about legal reasoning that advances our analysis of cogent argument.

The inadequacy of the New Rhetoric is further illustrated by the attempt of Professor Julius Stone to apply the rhetorical theory to analysis of legal problems. ${ }^{162}$ The strongest statement derivable from his discussion is that leading precedents serve as seats of argument, im Perelman's language, or as Aristotle's topoi. ${ }^{163}$ Stone acknowledges the limited contribution which this observation makes. ${ }^{164}$ The Rhetorical theory leaves unanswered, inter alia, the pivotal question of low legal topoi, and other reasons offered for a proposition, may decide an issue correctly, or be said to justify a given ruling.

\section{Modern Philosophical Contributions}

The glaring defects in a theory of reasoning resting primarily on persuasion redouble the incentive to find a test of reasoning which analyzes the reasons themselves, and not the reaction of an audience, however sophisticated it may be. Certain problems evident in the rhetorical approach and traditional logic remain in any deductive reasoning context. For example, the premises from which the conclusions spring will

155. Perelman, supra note 152, at 216; Cf. Stoeckli, supra note 146, at 590.

156. See, e.g., Perelman, supra note 152, at 220.

157. Treatise 196-97 [264-67], 200 [269], 414-15 [554-55].

158. Id. at 59 [78-79].

159. Id. at 59-60 [78-79], 131 [176].

160. Christie, supra note 45, at 1325. See generally Treatise 241 [325], 351 [472], 354-57 [479-80].

161. Id. at 373-74 [502-03].

162. J. STONE, supra note 18, at 325-37.

163. Id. at 334-35.

164. Id. at 335 . 
often be less than certain or universal propositions. They are often working hypotheses of fact or legal principle, both of which are defeasible. Thus, the conclusions drawn will be entailed by the premises; but due to the nature of the premises they will be correspondingly qualified.

In addition, the language and concepts employed in the premises will necessarily be imprecise. While thorough attention to common and special usage as well as prior legal discussions of key terms may reduce ambiguity, eradication of the problem is very unlikely.

Acknowledging these problems, which after all afflict every manner of discourse, we may shift our attention to the question of justifiability. Where the rhetorician measures argument by results, the philosophical search for a justifiable mode of practical reasoning focuses on the content and interrelationship of the reasons offered in a specific context.

Because of their rigorous attention to particulars, many contemporary philosophers have provided enlightening discussions of practical reasoning. ${ }^{165}$ However, none of the present literature deals at any length with the legal context, ${ }^{166}$ and hittle emphasis is given to the problem of competing deductions. The nature of the practical reasoning which occurs in this discipline, therefore, remains essentially unexamined.

\section{V \\ Philosophical Excursus: Prolegomena to a Detailed Analysis of Good Legal Reasons}

This section will attempt to take a broad view of the outlines of the process of arguing with deductive reasons in contexts where no simple deduction settling a legal issue can be formulated. ${ }^{167}$ Such an overview of this admittedly extensive area of legal philosophy is desirable; what is

165. See, e.g., D. Gauthier, Practical Reasoning (1963); S. Toullmon, The UsES OF ARgument (1958). Works of lesser catholicity include: H. AIKEN, REason and Conduct (1962); K. Baier, The Moral Point Of VIEW: A Rational Basis of Ethics (1958); R. Beardsmore, Moral Reasoning (1969); P. Diesing, Reason in Society (1962); A. Murphy, The Theory of Practical Reason (1965); J. Passmore, Philosophical Reasoning (1961).

166. But cf. S. Tourman, supra note 165 (occasional use of a legal strawman in ethical contexts).

167. Cf. Wheatley, Reasons for Acting, 7 Dialogue 553 (1969). Professor Wisdom's famous metaphor that reasons serve as "legs of a chair" cooperating to support a conclusion rather than as "links of a cliain" entailing a result [Wisdom, Gods, in EsSAYS ON LOGIC AND LANGUAGE 195 (A. Flew ed. 1961)] is often cited by legal philosophers in conjuction with their discussions of Perelman's work on argument. See, e.g., J. STONE, supra note 18, at 327. However, Wisdom, like Austin [see, e.g., J. Austin, Phinosophical Papers, 123, 134-35 (1961)], apparently assumes that a non-deductive structure governs such discourse. Even so, Wisdom, unlike Perelman, is interested in truth or validity in supportive argument, not in persuasion. 
lost in detail is more than compensated for by increased perspective. The topic area includes the entire spectrum of contexts in which reasons are offered for legal propositions, thus raising the issue of the justification of the conclusion.

\section{A. On Being a Reason}

Reasons for legal positions are frequently not completely stated or explicitly formulated. ${ }^{168}$ Nevertheless, it is evident from the preceding discussion $^{169}$ that a statement must be capable of being stated in the following general form if it is to be a reason for a legal conclusion:

$R_{g}: \quad R$ appears in light of present knowledge (i) to be a true statement, and (ii) to support (confirm, render more probable) the conclusion by virtue of its role as a minor premise in a deductive argument.

In the remainder of this part the designation $R$ refers to fully explicit reasons, true statements which fit the form above and support the conclusion. The patterns of argument outlined will be concerned with fully explicit reasons for adopting (pursuing, and so on) legal position $X$ [denominated $R(X)]$ and against adopting position $X[R($ Not- $X)$ ], and statements about such reasons.

\section{B. Arguing with Reasons}

That a stateinent, or set of statements, fulfills the conditions for being a reason for $X$ legal position does not mean it constitutes a decisive reason, or reason sufficient to justify adopting $X$. Even in the abstract this is not surprising; legal issues are usually complicated enough that there will alınost always be reasons for not adopting any conteinplated legal position as well as reasons for going ahead with it. A general approach to this problem is set out below. Argnments of the form shown here have many parallels in other realms of discourse, such as ethics, although there are no close analogies between these legal arguments and forms of argument in other disciplines.

Because of the meaning of the term, an argunnent with reasons is a deductive operation. To reach the conclusion that a given position is justified requires utilization of a major premise dealing with justification and a minor premise establishing satisfaction of the first premise's criteria.

The classic and simplest form of practical argument to the conclusion that $X$ legal position should be adopted is:

168. See note 85 supra and accompanying text.

169. See text accompanying notes 72-97 supra. For statement of factors which may bear on the weight of a reason, see M. Scriven, PrIMary PHiLosophy 56-62 (1966). 
Whatever accords with $P$ [A statement of (i) precedential or statutory rule, or (ii) legal principle or doctrine, or (iii) in-

$F_{1} \quad$ terests of someone] is a justified position.

$X$ furthers (or accords with) $P$.

Therefore, $X$ is a justifiable position.

This form of argument, while a common procedure in casuistry, works only where $P$ is a universally applicable (indefeasible) proposition which, in addition, takes precedence over any other proposition that might conflict with it. Since a great number of propositions have defeating exceptions and since few rules would meet the second requirement, this form of argument has little or no utility in real life.

Most practical arguments inake different use of the legal principles and social interests involved. Instead of relying on a universal premise, they offer inore qualified deductive reasons to support a legal position. A valid argument with reasons, however, is much more complex than:

$F_{2} \quad R(X)$.
Therefore, $X$ is a justifed position.

Form $F_{2}$ is simply a restatement of the first form of argument with the major premise implied but left unstated.

The simplest (but only the simplest) valid form of legal argument based on deductive supporting reasons for a conclusion of the form "Therefore, $X$ is a justified legal position" is the following:

The legal position supported by the stronger reasons is justified.

$F_{3} \quad R(X)$.

There are no reasons against adopting $X$.

Therefore, $X$ is a justified legal position.

Naturally, given the complexity and interdependence of legal issues, this straightforward argument-form is not often apposite. Virtually every aspect of the legal process has wider ramifications and rare is the issue which does not affect two concerns differently. However, it is easy to see a general argument-form which is always applicable if a truth value can be assigned to its premises:

The legal position supported by the stronger reasons is justified.

$R(X)_{1} \ldots R(X)_{\mathrm{n}}$ are all the reasons to adopt $X$.

$F_{4} \quad R(\text { Not }-X)_{1} \ldots R(\text { Not } X)_{\mathrm{m}}$ are all the reasons not to adopt $X$.

$F_{4} \quad$ The combined reasons $R(X)_{1} \ldots R(X)_{n}$ are stronger than the combined reasons $R(\text { Not- } X)_{1} \ldots R(\text { Not } X)_{m}$.

Therefore, $X$ is a justified legal position.

This structure is a completely valid argument form though a number of subsidiary arguments are possible: whether the lists of reasons offered are exhaustive, whether each of the putative reasons is actually a reason for the conclusion, and so on. The latter arguments concern the truth of the premises and do not affect the validity of the general argument form. 
A simplified version of $F_{4}$ is used in practice far more often than $F_{4}$ itself because of the difficulty encountered in establishing the first two premises of that argument schema:

The legal position supported by the stronger reasons is justified.

A diligent search has been made to amass all reasons relevant to $X$, the results of which are reflected here.

$F_{5} \quad R(X)_{1} \ldots R(X)_{n}$.

$R(\text { Not- } X)_{1} \ldots R(\text { Not- } X)_{\mathrm{m}}$.

$R(X)_{1-\mathrm{n}}$ are stronger than $R(\text { Not- } X)_{1-\mathrm{m}}$.

Therefore, $X$ is a justified legal position.

Modifications and qualifications on the argument forms discussed are necessary in the case of conflicting competing legal outcomes. The greater weight of $R(X)_{1-n}$ over $R(\text { Not- } X)_{1-m}$ is not always going to mean that $X$ legal position should be taken. This judgment speaks to the decision between $X$ and Not- $X$, and leaves out comparison of $X$ with other outcomes. An unsophisticated schema considerimg this conflict would be:

The legal position supported by the stronger reasons is justified.

$X$ is characterized by $R(X)_{1-\mathrm{n}}$ and $R(\operatorname{Not}-X)_{1-\mathrm{m}}$.

$F_{6} \quad Y$ is characterized by $R(Y)_{1-\mathrm{n}}$ and $R(\text { Not- } Y)_{1-\mathrm{m}}$.

$F_{B} \quad X$ and $Y$ are the ouly competing outcomes.

$X$ is supported by the stronger reasons.

Therefore, $X$ is a justified legal position.

Modifications parallel to earlier distinctions would be necessary to handle such factors as the difficulty of proving the absence of other competing legal positions:

The legal position supported by the stronger reasons is justified.

$X$ is characterized by $R(X)_{1_{-n}}$ and $R(\operatorname{Not}-X)_{1^{-} \mathrm{m}}$.

$\mathrm{Y}$ is characterized by $R(Y)_{1_{-\mathrm{n}}}$ and $R(\text { Not- } Y)_{1_{-m^{-}}}$.

$F_{7}$ No other legal positions are known [have been argued] to be viable options.

$X$ is supported by the stronger reasons.

Therefore, $X$ is a justified legal positon.

The difficulty with $F_{4-7}$ lies not with the premises stating the reasons for and against $X$ and $Y$ or with those excluding alternatives, but with the comparative strength premise, " $X$ is supported by the stronger reasons," and in the major premise on justification carried in each argument.

\section{Justifying the Conclusion}

Two distinct questions arise at this point. The first is whether the comparative strength premise is capable of rational determination. The second is the more basic inquiry as to whether an argument with a firmly proven comparative strength premise actually establishlies a jus- 
tification for adopting a given legal position beyond showing that it is the most reason-supported outcome.

The comparative strength premise seems at first glance to be immune to rational testing; its truth value may not be assessed. But upon analysis this conclusion does not appear to be correct. We are not accustomed to "proving" a comparison, but argument over the comparative weights of different sorts of considerations is hardly beyond the ken of reason. It is easy to envision subsidiary deductive arguments on the question of what sorts of reasons are the most significant. ${ }^{170}$

The question of justification is more troublesome: it may not be clear that we want to say that a plurality of reasons justifies a legal position. The point is important because the justification for a deductive conclusion is not questioned once the premises on which it is based have been established. A comfortable confidence in the conclusions of practical reasoning is desirable and, perhaps, essential if this form of argument is to claim any superiority over the rhetorical approach. So, we must assess the major premise, "the legal position supported by the stronger reasons is justified."

Practical deductive reasoning is, by definition, tested by more objective standards than audience reaction. Of course, Perelman's audience ${ }^{171}$ may be thinking analytically. But the focus of the New Rhetoric is on personal behavior and not on the relationships between various concepts and facts of reality. In practical deductive reasoning, content, and not effect, is the issue, the conceptual structure of our minds and language, and not our psychological responses. Then too, rhetoric is committed to the view that differences are in principle unresolvable due to the inherent relativity of values. ${ }^{172}$ In a world where differences must be resolved and where legal doctrine must be applied, altered, and evaluated, the canons of practical reason appear far preferable because they speak to the most important problems.

The question of justification is bound up with the issue of demonstrability. ${ }^{173}$ The issue might be phrased as whether it is ever possible to be sure that every relevant reason has been correctly weighed, every aspect of a legal situation examined, every effect of every possible outcome considered, so that no possible doubt remains about the advisability of a given legal position. But the quest for a demonstrative certainty that $X$ legal position ought to be adopted in a given context is misdirected.

170. For example, "Greatest weight should be given to reasons advancing policies $P \& Q ; R(X)_{1-n}$ advance $P \& Q$; therefore, greatest weight should be given to $R(X)$ $1-n^{\prime \prime}$

171. See text accoinpanying notes 136-42 supra.

172. See text accompanying notes 148-56 supra.

173. Cf. D. GaUTHIER, supra note 165 , at $48-49$. 
The short answer to questions such as these is that demonstrability is possible only if the context of the problem is artificially restricted. If stringent conditions are laid down for the relevance of reasons, if possible competing outcomes and their potential effects are fully determinable, it might be possible to show conclusively what ought to be done in a given case. In practice these conditions are never met. It must be remembered, though, that practical reasoning does not occur in a vacuum; it operates on a discrete legal question presented to specified actors at soine isolated stage of the process. It is this context-dependence that gives rise to justified conclusions.

The relation of practical problems to their contexts is of primary importance in considering the methods of practical reasoning. ${ }^{174}$ The methods must enable us to solve a problem under the limitations which are imposed by the context. It is quite mappropriate to employ ideal standards in justifying practical judgments; the standards must evaluate the practical argument as a contribution to the solution of an actual problem. ${ }^{175}$

In any reasoning, one may discredit the conclusions drawn by showing the falsity of the factual assumptions underlying the premises. Thus, no special or unique infirmity afflicts practical arguments employing reasons in a deductive context. Moreover, actors in the legal process are not called upon to decide truths for all time, rather they must deal with selection of competing legal positions in a limited context, though the outer boundary of relevant concerns may be vague. A process of giving reasons is particularly well suited to this task, especially since the basic deductive structure forces consideration of the underlying factors and issues. Since no immutable conclusions are to be drawn, there is every justification for accepting the most rational solution available at the time.

The dynamic aspect of the practical reasoning context also affects the question of justification. Although we consider various alternative legal outcomes before selecting one, we adopt one outcome reflecting the influence of previous and present developments as well as of what we now propose to adopt and of what we expect to happen subsequently. Since the legal world does not stop to facilitate solution of practical problems, a standard of justification for practical legal judgments which does not take account of the dynamic context is unrealistic, and, perhaps, seriously debilitating. A rigorous utilitarian analysis of the reasons offered is crucial to proper developinent of the comparative strength premise. This commitment should not obscure the fact that a practical legal question must depend largely on an appeal to a context of activity which al-

174. See, W. ZeLERMYer, supra note 7 , at 8 .

175. D. GAUTHIER, supra note 165 , at 2. 
ready carries the imprint of a general pattern of law. Practical reasoning often consists in showing that a given legal position under consideration fits into such a context better than others would.

In view of the context-dependence of practical reasoning and the necessity of decision in legal problems, it would be irrational not to adopt the position supported by the greatest weight of reasons. ${ }^{176}$ Since we are concerned here with situations in which formal deduction conclusions do not resolve the issue, practical weighing of reasons is the only avenue open for cognitive inquiry. Solving the problem posed by the legal question necessitates resort to reasons.

The energing canons of practical reasoning cannot remove the possibility of disagreement about reasons for legal positions. However, in an adversary system such conflict would be sorely missed if absent; it provides the prime impetus for continued reevaluation of doctrine, giving us hope of keeping the legal world abreast of the evolution of the rest of society. It thus returns us to reflection on the bases of practical reasoning. The question of what are good and sufficient reasons for a given legal position must be arduously pursued; the account presented here is an invitation to join the debate.

\section{CONCLUSION}

Important advances are being made in the study of legal rationality. The theories of deontic ${ }^{177}$ and modal ${ }^{178}$ logic are advancing rapidly, providing important insights into the structure of such concepts as permission, prohibition and obligation. ${ }^{179}$ Symbolic logics are proposed as a means of analyzing complex documents and statutes. ${ }^{180}$ Decision theory and game theory are also being utilized in the analysis of some legal questions. ${ }^{181}$

A comprehensive theory of legal reasoning, lowever, is absent. A series of interdependent factors appears, in retrospect, to have brought about the present confusion in the theory of legal reasoning. Reaction to Austinian mechamisin led to inaccurate de-emphasis on deduction and

176. Cf. id. at 17.

177. Deontic logic deals with the concepts of obligation and prohibition. See J. STONE, supra note 18, at 186-87, 192-97; cf. G. VON WRIGHT, AN ESSAY IN MODAL LOGIC (1951).

178. Modal logic studies the logical features of the concepts of necessity, possibility, impossibjlity and related ideas. 5 ENCY. OF PHILOSOPHY 5 (1967).

179. See Cullison, Logical Analysis of Legal Doctrine, 53 Iowa L. Rev. 1209 (1968); $c f$. W. HoHFELd, FundaMental Legal CONCEPTIONS (1923).

180. Allen, Symbolic Logic, 66 YaLE L.J. 833 (1957).

181. See, e.g., Birmingham, The Generality of Neutral Principles: A GameTheoretic Perspective, 58 CALIF. L. REv. 873 (1970); Kaplan, Decision Theory and the Factfinding Process, 20 STAN. L. REv. 1065 (1968). 
a corresponding stress on induction and analogy, which appear on reflection to be far less important factors.

The analysis of legal reasoning, therefore, must shift to a new focus: the pervasive and fundamental process by which reasons are offered in the form of deductive arguments, the valid conclusions of which speak to, but do not resolve, certain legal propositions. The New Rhetoric movement reflects the realization that deductive arguments often cannot be formulated strongly enough to settle a legal issue conclusively. However, the rhetorical theory suffers froin prostrating value relativism and a commitment to audience persuasion as the test of a valid argument. A more justifiable process, centered on the weight and content of supportive deductive reasoning, has yet to be explored; the description offered here is but a first step.

Bochenski has persuasively argued that in humane science every available method of analysis nust be utilized. ${ }^{182}$ But in the law, only what is rationally proven may be legitimately recoguized if justice is to be more than fiat and philosophy more than poetry.

Kent Sinclair, Jr.

182. J. BochensKí, The Methods of CONTEMPorary ThOUght 126 (1965). 